\title{
Fatores de risco e soroprevalência da brucelose em assentamento rural no município de Aragominas - TO, Brasil
}

ISSN

1809-9475

\section{Risk factors and soroprevalence of brucelosis in rural area in the district of Aragominas, Tocantins - Brazil.}

\section{Márcio Pedrote Carvalho \\ Luciana Sant Ana Souza \\ Jair Antonio Carvalho \\ Bruno Medrado Araújo}

Palavras-chave:

Animais

soropositivos

Defesa

Agropecuária

Provas

Sorológicas

Zoonoses
Artigo
Original

Original

Paper $12 / 2012$

Aprovado em $08 / 2013$
Recebido em

\section{Resumo:}

Foi realizado um estudo descritivo transversal ou de prevalência, com o objetivo de identificar a positividade de reações sorológicas para brucelose em bovinos, em projeto de assentamento do Município de Aragominas, Estado do Tocantins, Brasil, no ano de 2008. Neste estudo a amostra foi constituída de 198 bovinos submetidos à provas sorológicas para brucelose. Conforme preconizado pelo Programa de Controle e Erradicação da Brucelose e Tuberculose - PNCEBT, as provas realizadas foram, de triagem a prova do Antígeno Acidificado Tamponado (AAT), realizada no laboratório de Fundação de Medicina Tropical e confirmatória a prova de 2 mercaptoetanol (2 ME), realizada no laboratório de Microbiologia da Universidade Federal do Tocantins - UFT. Fatores relacionados à transmissão da brucelose foram observados com a finalidade de avaliar o potencial da região em apresentar animais soropositivos, onde constatou - se um elevado risco para brucelose. O índice de ocorrência de aborto é bem pequeno, pois $91,9 \%$ alegaram não observar tal problema nos últimos 12 meses, fato esse que pode ser justificado pela baixa frequência de animais soropositivos para brucelose bovina encontrada no projeto de assentamento $(0,5 \%)$, o que sugere sucesso das ações propostas pelo Programa de Controle da doença, exigidas nos últimos quatro anos.

\begin{abstract}
:
It was performed a transversal descriptive study or prevalence, with the purpose of identifying the positivity of sorological reactions for brucellosis in bovines, in a rural site project in the District of Aragominas, State of Tocantins, Brazil, in the year of 2008. In this study the sample was formed by 198 bovines under sorological tests for brucellosis. According to what is preconized by the Control and Eradication Program for Brucellosis and Tuberculosis, the tests performed were selection for Tamponated Acidified Antigenous Test $(A A T)$, performed in the laboratory of Tropical Medicine Foundation and confirmation for 2 Mercaptoctanol test (2 ME), performed in the Microbiology Laboratory of Tocantins Federal University (UFT). Factors related to brucellosis transmission were observed with the purpose of assessing the region potential in presenting soropositive animals, where it was shown a high risk for Brucellosis. The aborption occurrence level is quite small, so 91,9\% haven't observed such a problem in the last 12 months. This fact can be justified by the low frequency of soropositive animals for bovine brucellosis found in the rural site project $(0,5 \%)$, what suggests success in the actions proposed by the Disease Control Program, requested in the last four years.
\end{abstract}

Keywords:

Agropecuary

Defense

Soropositive

Animals

Sorological Tests

Zoonosis 


\section{Introdução}

A brucelose é uma enfermidade infecciosa que causa graves perdas econômicas na produção animal e na saúde pública pelo acometimento de seres humanos. A presença dessa doença em uma região ou país resulta em custos diretos ou indiretos para as propriedades rurais e para indústria animal, tais como redução no preço da carne, do leite e derivados; desvalorização dos produtos para mercado externo; altos custos com pesquisas, programas de controle e erradicação (LAUAR, 1983; TEIXEIRA et al.,1998).

Causada por bactérias do gênero Brucella $s p$ a brucelose é uma doença de características zoonóticas. Encontra-se amplamente distribuída no mundo, sendo que os animais atuam como hospedeiros primários, essenciais para a persistência dos focos de infecção, e os seres humanos como hospedeiros acidentais, terminais, pouco eficientes na perpetuação da mesma (WHO, 1986; USABIAGA, 2001).

No gênero brucella, se reconhecem, atualmente, seis espécies: $B$. melitensis, $B$. abortus, B. suis, B. neotomae, B. ovis e B. canis. As três primeiras, denominadas clássicas são subdivididas em biovares, que se distinguem por diferenças de características bioquímicas, de comportamento ou ambas, frente a soros mono específicos $A$. (abortus) e $M$. (melitensis) (LUCERO et al., 2003).

A infecção dos bovinos se dá por via digestiva, por meio de alimento contaminado com Brucella sp, tais como: feto abortado, envoltórios fetais e descargas vaginais. A transmissão entre rebanhos acontece quando se adquire animais infectados de outros rebanhos, proximidade de rebanhos infectados, que compartilham pastagem e animais que se alimentam de outro em decomposição (RADOSTITS et al. 2000).

Estudos têm avaliado a importância do touro na difusão da brucelose, com demonstração clara de que nos bovinos em monta natural a transmissão venérea tem pouca importância (CAMPERO, 1993). Já na inseminação artificial, a contaminação pode-se instalar com maior frequência, se o doador estiver infectado (LANGENEGGER, 1992; POESTER, 1997).
Conforme os dados oficiais divulgados pelo Ministério da Agricultura Pecuária e Abastecimento (MAPA), estudos realizados entre 1988 e 1998 indicaram uma prevalência de animais soropositivos para brucelose no Brasil variando entre $4 \%$ e $5 \%$ (BRASIL, 2003).

Outros estudos mais recentes com bovinos de aptidões variadas (leite, carne e mista), mostram uma soroprevalência em rebanhos bovinos variando de $10,6 \%$ a $82,0 \%$ e em animais do mesmo rebanho, variando entre $1,9 \%$ a 10,2\% (TOCANTINS, 2000; RIBEIRO et al., 2003; MATO GROSSO, 2004; MONTEIRO et al., 2006).

Em rebanhos leiteiros, as frequências de infecção pela detecção de anticorpos contra B. abortus, no Brasil, podem variar de $1,22 \%$, conforme Poletto et al. (2004) realizando estudo em Passo Fundo - Rio Grande do Sul; a 16,49\%, conforme trabalho de Palmquist (2001) no estado do Paraná.

Em alguns trabalhos, tem sido observado que há mais chances de ocorrência da infecção por brucelose em sistemas de exploração de corte, como os apresentados por Poester et al. (2002) e Monteiro et al. (2006), em que os rebanhos de corte tiveram 2,82 vezes mais chances de apresentar a doença que os rebanhos leiteiros, o que possivelmente estaria relacionado ao maior fluxo de entrada e saída de animais da propriedade nesse tipo de exploração.

Em rebanhos bovinos, a brucelose provoca aborto, causa esterilidade temporária ou permanente, repetição de cio e perdas na produção de leite por mastites específicas (LAUAR, 1983). Estima em 25\% de perda em produção de leite, bem como em $15 \%$ de perda na produção de bezerros (BRASIL, 2006)

Lucas (2006), trabalhando com rebanhos leiteiros com prevalência de $0,06 \%$ para os estados de Minas Gerais e Goiás, e de 3,0\% para Santa Catarina e Rio Grande do Sul, calculou o impacto econômico da brucelose nesses rebanhos e obteve o percentual do prejuízo em reais na receita total por ano de $5 \%$ a $13 \%$, respectivamente, para as duas regiões. Prejuízo esse que assume proporções elevadas na rentabilidade do produtor.

A resposta imunológica em animais pós-infecção ou vacinação é produzida a partir da 
primeira semana, aparecendo, em primeiro lugar, o isotipo $\operatorname{IgM}$ e, logo após, o IgG1. As respostas de IgG2 e IgA aparecem mais tarde, aumentam gradativamente, mas permanecem em níveis baixos. A observação por períodos prolongados da resposta humoral em animais infectados demonstra que há um leve decréscimo dos níveis de $\operatorname{IgM}$, enquanto que os de IgG1 permanecem altos, inalterados. A IgG2 e IgA permanecem em níveis mais baixos e estáveis (BRASIL, 2006).

A observação por período prolongado em animais vacinados com B19, quando vacinados até 8 meses, demonstra que o nível de anticorpos decresce rapidamente, atingindo títulos inferiores a 25 UI depois de 12 meses. Por outro lado, se a vacinação for realizada acima de 8 meses de idade, os títulos vacinais tendem a permanecer elevados por mais tempo, podendo gerar reações falso - positivas nos testes indiretos de diagnóstico (BRASIL, 2006).

A vacinação contra brucelose, atualmente, mais utilizada no Brasil é a B19, composta com uma amostra de B. abortus lisa, isolada do leite de uma vaca Jersey em 1923, que depois de acidentalmente esquecida por mais de um ano à temperatura ambiente perdeu virulência, sendo utilizada como vacina desde a década de 1930. A B19 é atenuada para fêmeas jovens e pode, no entanto, causar orquite em machos e aborto se administrada durante a gestação (BRASIL, 2006).

Por ser uma amostra lisa de B. abortus, induz formação de anticorpos específicos contra o LPS liso e pode interferir no diagnóstico sorológico da Brucelose, causando a grande maioria dos falsos positivos no teste de soroaglutinação (ALTON, 1975). Uma vez que a persistência desses anticorpos esta relacionada à idade de vacinação, se as fêmeas forem vacinadas com a idade superior a 8 meses, há grande probabilidade da produção de anticorpos perdurar e interferir no diagnóstico da doença após os 24 meses de idade. Com a vacinação efetuada até os 8 meses de idade, tais anticorpos desaparecem e os animais com idade superior a 24 meses são totalmente negativos às provas sorológicas (BRASIL, 2006).

Outro tipo de vacina é a RB 51, que foi elaborada de uma amostra de B. abortus rugosa atenuada, originada da amostra lisa virulenta 2308, uma mutante rugosa que so- freu passagens sucessivas em meio contendo concentrações subinibitórias de rifampicina.

Possui características de proteção semelhantes às da $\mathrm{B} 19$, porém, por ser uma amostra rugosa, não induz a formação de anticorpos anti-LPS liso (aglutinantes), não interferindo assim no diagnóstico sorológico da doença (BRASIL, 2006; LORD, 1998).

Dentre os testes sorológicos mais comumente utilizados para o diagnóstico da brucelose, destacam-se o Antígeno Acidificado Tamponado (AAT) como prova de triagem e o 2-Mercaptoetanol (2 ME) que é mais específico como prova confirmatória.

O AAT é preparado com o antígeno na concentração de $8 \%$, tamponado em pH ácido $(3,6)$ e corado com Rosa de Bengala. Essa acidificação do antígeno reduz a atividade da IgM, tornando a prova seletiva para identificação da subclasse IgG1. A maioria dos soros de animais bacteriologicamente positivos apresenta reação a essa prova, porém, possui uma grande sensibilidade com a vacina B19. É uma prova qualitativa, pois não indica o título de anticorpos do soro testado, detecta com maior precocidade as infecções recentes (BRASIL, 2006; CASAS OLASCOAGA, 1976).

O 2 ME é uma prova quantitativa seletiva que detecta somente a presença de IgG no soro, que é imunoglobulina indicativa de doença crônica (BRASIL, 2006). A prova fundamenta-se na ação de certos compostos que contém o radical tiol ( $2 \mathrm{ME}$ ), que degradam a configuração da IgM pentamérica em subunidades, determinando, assim, a perda de sua atividade aglutinante. Esse processo torna o teste sensível às aglutinações estabelecidas por toda a classe IgG (CASAS OLASCOAGA,1976). Nicoletti (1980) afirma que a prova de $2 \mathrm{ME}$ gera reações falso-positivas em menor quantidade do que o AAT.

Nos testes indiretos quantitativos, existe sempre um ponto de corte, ou seja, um determinado título de anticorpos, a partir do qual o teste é considerado positivo. Os valores de sensibilidade e especificidade de um determinado teste dependem do ponto de corte e estão inversamente relacionados. Se o ponto de corte do teste diagnóstico for modificado para aumentar a sensibilidade, a especificidade diminuirá. De maneira inversa, se o ponto de corte do teste diagnóstico for modificado 
para elevar a especificidade, haverá perda de sensibilidade (BRASIL, 2006).

No Brasil, durante a década de 70 , se consolidou a necessidade do controle da brucelose. Assim, em 1976, o Ministério da Agricultura aprovou a Portaria 23/76, na qual se estabelece o controle nacional desta doença (BRASIL, 1976).

No entanto, as medidas adotadas por essa Portaria foram consideradas pouco efetivas, não conseguindo desenvolver um programa estruturado que criasse estímulo para que os criadores adotassem as medidas necessárias ao controle e erradicação da brucelose. Isso se traduziu na pouca variação dos indicadores da enfermidade no período analisado, com registro de $4,9 \%$ em 1975, cujas cifras variaram entre $2,5 \%$, na região Nordeste, até $7,5 \%$, na região Sudeste; enquanto em 1998, o estimado foi entre $4 \%$ e $5 \%$ (BRASIL, 1988). Por esse motivo, no ano de 2001, o Ministério da Agricultura e Abastecimento publicou uma portaria, na qual se instituiu o Programa Nacional de Controle e Erradicação da Brucelose e da Tuberculose Animal (PNCEBT), com previsão de implantação gradativa até 2003 (BRASIL, 2001).

Dentre as mudanças previstas no PNCEBT, estava a vacinação obrigatória, a declaração de vacina de fêmeas bovinas de três a oito meses, e adoção da prova do Antígeno Acidificado Tamponado como teste de triagem, bem como, da prova do 2-mecaptoetanol como teste confirmatório. Medidas que representam avanços quando relacionadas ao que previa a legislação anterior, ou seja, o diagnóstico sorológico da brucelose baseado apenas na prova de soroaglutinação em placa, a qual pode apresentar problema tanto de falta de sensibilidade quanto de falta de especificidade (MURAKAMI, 2003).

Por ser uma zoonose, a brucelose em rebanhos resulta em infecções humanas. $\mathrm{Na}$ maioria das vezes, quando a enfermidade não é tratada na fase aguda, o custo crônico da doença no homem produz perdas econômicas de vulto. Essas perdas estão relacionadas com custo de diagnósticos e tratamento, muitas vezes requerendo internações prolongadas. Além disso, não deve ser esquecido o custo do período decorrente da ausência do trabalho (BRASIL, 2006).

As informações sobre a brucelose humana em países do Continente Americano são escassas, provavelmente devido à falta de diagnóstico e a subnotificação, no entanto, dados de 20 países das Américas, obtidos durante os anos de 1994 e 1998, relatam 29.132 casos em humanos (USABIAGA, 2001). No entanto, na maioria desses países, se estima que as estatísticas oficiais não reflitam a cifra real de pessoas com a doença, havendo um sub-registro que varia entre 10 e 25 vezes os valores reais, o que tem sido atribuído, em parte, a erros diagnósticos ou a falta de declaração, e, consecutivamente, ausência de fluxo através do sistema de informação (ALVAREZ et al., 2000).

Em pesquisa realizada pelo Centro Panamericano de Febre Aftosa (2000), foi enfatizado como um dos determinantes mais frequentes para o aparecimento de casos de brucelose humana, a baixa cobertura vacinal em bovinos.

Pouco se conhece sobre a prevalência de brucelose no rebanho tocantinense, principalmente em assentamentos rurais que têm características de grande fluxo de animais entre propriedades e consumo de leite e derivados por parte dos assentados. Para tanto, foi realizado este estudo com o objetivo de estudar a prevalência de brucelose no rebanho bovino, fatores de risco associados a essa enfermidade e avaliar a efetividade das ações do Programa Nacional de Controle e Erradicação da Brucelose e Tuberculose - PNCEBT.

O presente trabalho tem como objetivo Avaliar a efetividade das ações propostas pelo Programa Nacional de Controle e Erradicação da Brucelose e Tuberculose - PNCEBT. Através de Estudo dos fatores de risco e a prevalência de soropositividade para brucelose em bovinos. 


\section{Metodologia}

\section{1. Área de estudo}

O estudo foi realizado em um assentamento no Município de Aragominas - TO, distante 62 $\mathrm{km}$ ao noroeste de sua sede. A cidade possui localização geográfica entre latitude - $07^{\circ} 09^{\prime} 42^{\prime}$ 'S e longitude - 48 $31^{\circ} 42^{\prime}$ ' W. O município conta com uma área de $1.173 \mathrm{~km}^{2}$, vegetação predominante de floresta amazônica, clima tropical, índice pluviométrico anual $1.700 \mathrm{~mm}$ e população bovina de 69.681 animais.

\subsection{Amostragem}

Foi realizado um estudo descritivo transversal ou de prevalência (BENSEÑOR \& LOTUFO, 2005; MEDRONHO et al., 2006), onde foram amostradas todas as propriedades do assentamento com rebanho que, segundo a ADAPEC - Agência de Defesa Agropecuária do Tocantins, conta com um efetivo bovino de 3.156 cabeças.

Foram estimados dois níveis de prevalência da brucelose bovina: a prevalência em propriedade, a qual será considerada positiva a existência de apenas um animal, e a prevalência em animais soropositivos.

Na prevalência para animais soropositivos, considerando-se a escassez de dados representativos regionais, para conferir maior exatidão e representatividade, foi utilizada a maior taxa prevalência para o país a partir de dados oficiais do Ministério da Agricultura (5\%) com o acréscimo de possíveis perdas com a utilização pela adoção de método de amostragem probabilística estratificada, usando, dessa forma, uma estimativa de prevalência da infecção de $15 \%$. Foram adotados erro máximo de $5 \%$ e grau de confiança de 95\% da prevalência (SAMPAIO, 2007), tendo-se obtido o número aproximado de 196 animais.

Foram adotados os seguintes critérios de inclusão de animais na pesquisa: serem fêmeas, terem idade superior ou igual 24 meses, apresentarem-se fora do intervalo de 15 dias antes e 15 dias após o parto, segundo normatização do PNCEBT, e estarem em condições de normalidade.

\subsection{Obtenção da amostragem}

As amostras sanguíneas dos animais foram obtidas após a leitura e consentimento do proprietário, para a inclusão da propriedade na colheita de sangue, e essa foi realizada em animais aleatoriamente escolhidos, sendo colhidas de 15 a $20 \mathrm{ml}$ de sangue, por meio de punção da veia jugular, em tubos vacutainer sem anticoagulante. Essas amostras foram posteriormente centrifugadas e os soros sanguíneos obtidos foram estocados em tubos $e p$ pendorf a uma temperatura de $20^{\circ}$ negativos e, posteriormente, submetidos aos testes de diagnóstico de Brucelose.

Para procedimentos de identificação de amostras colhidas, foi utilizado um código de identificação contendo uma letra "B" o que identifica a amostra proveniente da espécie bovina, numeração de "01 a 57" identificando o número da propriedade (lote) do assentamento em conformidade à numeração realizada pelo Instituto Nacional de Colonização e Reforma Agrária - INCRA, e, por fim, a numeração que identifica o animal. Adotou-se também uma planilha de identificação e caracterização dos animais amostrados, contendo dados como idade, número de parições, ocorrência de aborto e vacinações contra enfermidades da esfera reprodutiva.

\subsection{Testes de diagnóstico}

Como teste de triagem, foi realizada a prova de soroaglutinação pelo Antígeno Acidificado Tamponado (rosa bengala), conforme preconizado pelo Programa Nacional de Controle e Erradicação da Brucelose e Tuberculose Animal - PNCEBT (BRASIL, 2001). Os soros reagentes ao teste de triagem foram submetidos à prova confirmatória de 2 ME (2-mercaptoetanol).

A prova de Antígeno Acidificado Tamponado (AAT) foi realizada no laboratório da Fundação de Medicina Tropical FMT, sendo o teste confirmatório de 2-mercaptoetanol $(2 \mathrm{ME})$ realizado em laboratório da Universidade Federal do Tocantins - UFT, seguindo protocolo preconizado pelo manual técnico do PNCEBT (BRASIL, 2001). 
Os resultados dos testes de diagnósticos para a prova de Antígeno Acidificado Tamponado - AAT foram positivos, negativos e inconclusivos, posteriormente, foram submetidas às amostras positivas e inconclusivas no $\mathrm{AAT}$, à prova confirmatória de 2-mercaptoetanol, obtendo resultados positivos e negativos. Posteriormente, foi classificada como positiva a propriedade que apresentou pelo menos um animal positivo à prova confirmatória, e negativa aquela que apresenta todos os animais com resultados negativos nas provas sorológicas.

\subsection{Questionário}

Foi aplicado um questionário, de forma simultânea à coleta das amostras em cada propriedade rural, preferencialmente ao proprietário ou, na ausência desse, a um funcionário da propriedade, o qual abordava fatores sócio-demográficos, manejo sanitário do rebanho, tipo de produção e consumo de leite e derivados "in natura".

\subsection{Análise estatística}

Os dados coletados, questionários, termos de consentimento e planilhas de identificação foram armazenados em um banco de dados no Laboratório de Pesquisa em Medicina Tropical.

Os dados coletados foram digitados no programa Microsoft Excel, criando um banco de dados.

\section{Resultados}

O Assentamento é constituído por 57 propriedades rurais, que apresentavam, segundo dados da ADAPEC, um efetivo de 3.156 animais da espécie bovina, distribuídos em 37 propriedades, estando assim 20 propriedades sem efetivo bovino. A média de tamanho dos lotes do assentamento está em torno de dez alqueires. O tipo de atividade predominante é a pecuária.

Com relação aos aspectos sócioeconômicos, foi observada uma renda familiar mais frequente de um a dois salários mínimos $(62,2 \%)$, seguida de até um salário mínimo $(35,1 \%)$, e com menor frequência de dois a três salários mínimos $(2,7 \%)$.
O grau de escolaridade encontrado mais frequentemente em trabalhadores rurais, que lidam diretamente com bovinos, foi o de primeiro grau incompleto $(73,0 \%)$, seguido de não alfabetizados $(10,8 \%)$, e o menos frequente de segundo grau incompleto $(2,7 \%)$.

O sistema de exploração pecuária predominante foi a bovinocultura de aptidão mista com uma porcentagem de $78,4 \%$, seguido da exploração leiteira e corte com um número mais reduzido. Em relação ao tipo de criação quanto ao manejo dos animais, o que se destacou foi a criação extensiva.

Das propriedades, $83,8 \%(\mathrm{~N}=31)$ produz leite, nenhuma possui ordenha tecnificada e não efetua mais de uma ordenha por dia. O leite produzido no assentamento em grande parte é consumido nas propriedades; $74,2 \%$, alguns produtores produzem e comercializam o queijo, e apenas $12,9 \%$ entregam leite a laticínios.

Todas as propriedades consomem leite e derivados, as que não produzem adquirem em propriedades próximas; $43,2 \%$ consomem queijo fresco, feito com leite in natura; $21,6 \%$ consomem leite in natura.

Com relação á comercialização de carne bovina no assentamento, a maior parte dos produtores abate seus animais na propriedade $(51,4 \%)$, seguido de abate em estabelecimento com inspeção veterinária, e dos que não abatem animais.

Grande parte destes produtores comercializa seu rebanho com outros produtores do próprio assentamento e com comerciantes de gado que passam por varias propriedades comprando e vendendo animais. O fluxo de fêmeas é frequente em todas as idades, sendo o de animais, no terço final de gestação, bastante significativo.

Quando perguntados sobre a ocorrência de aborto nos últimos 12 meses na propriedade, $8,1 \%$ relaram a ocorrência e $91,9 \%$ a ausência de abortos. No que diz respeito à manipulação de fetos e qual o destino desses, $89,2 \%$ relataram que deixavam no local e $10,8 \%$ que manipulavam para enterrar.

Dos 37 produtores questionados, todos relataram fazer movimento de rebanho bovino mediante a emissão de documento zoossanitário (Guia de Transito Animal - GTA) emitido pela Agência de Defesa Agropecuária - ADAPEC. 
$\mathrm{O}$ aluguel de pasto em determinadas épocas do ano é uma prática muito frequente com $51,4 \%$ das propriedades realizando essa atividade, $40,6 \%$ das propriedades tem pasto em comum com outras propriedades.

Com relação à reprodução bovina, o sistema de monta natural está presente em todas as propriedades, portanto, das propriedades trabalhadas, nenhuma utiliza a inseminação artificial como método de reprodução.

Os proprietários na totalidade $(\mathrm{N}=37)$ afirmam que realizam a vacinação contra brucelose em fêmeas bovinas, e que todas são realizadas por vacinador cadastrado na ADAPEC. A vacinação contra brucelose é amplamente praticada no assentamento, $16,2 \%$ dessas realizam apenas uma vacinação anual e 83,8\% realizam duas vacinações por ano.

Com relação à idade de vacinação dos animais, $70,3 \%$ dos produtores possuem conhecimento do que é preconizado pelo programa de controle que é a vacinação de fêmeas de 3 a 8 meses, e $94,6 \%$ deles realizam a marcação com ferro candente.

A forma em que a vacina é adquirida pelos produtores é praticamente a mesma na grande maioria das vezes: $97,3 \%$ das propriedades realizam a aquisição através do vacinador e $2,7 \%$ realizam a aquisição da vacina na loja com o receituário emitido pelo médico veterinário, como prevê o programa de controle, não sendo identificadas outras formas de aquisição de vacinas. Não houve relato de realização de exames no período da aquisição de animais e introdução na propriedade, tampouco exames de rotina realizados pelos produtores.

No planejamento para a colheita das amostras, o número mínimo obtido por meio do cálculo do tamanho da amostra foi 196 animais, foram colhidos soros de 198 animais de 37 propriedades de um projeto de assentamento de em Aragominas; 07 apresentaram resultados inconclusivos ou positivos para prova de Antígeno Acidificado Tamponado, os mesmos pertenciam a cinco propriedades.

Posteriormente, essas amostras foram encaminhadas para o teste confirmatório, conforme recomendado pelo PNCEBT, quando se obteve o resultado positivo para um animal de uma propriedade. Com esse resultado, a soroprevalência em animais do assentamento foi de $0,50 \%$ (1/198) e em propriedades de 2,70\% (1/37).
Essa propriedade possui tipo de exploração extensiva com aptidão para leite, com quatro animais de raça mestiça em lactação, produzindo em media 15 litros/dia, retirados em uma única ordenha diária, a maior quantidade do leite era destinada a um laticínio que recolhe leite da região e também ao consumo da propriedade.

Para animais de abate, o destino declarado pelo proprietário é o de estabelecimento com inspeção veterinária, porém, é declarada a compra e a venda de fêmeas para reprodução, o proprietário também aluga pasto em alguma época do ano, além de possuir área de pasto comum com outras propriedades. De acordo com o proprietário, não existe ocorrência de aborto nos últimos doze meses, e quando houve tal problema, o produtor evitou a manipulação do mesmo, deixando tal animal no local em que se encontrava.

\section{Discussão}

Os dados obtidos através do questionário aplicado aos produtores rurais do projeto de assentamento, os quais possuíam efetivos bovídeos em suas propriedades, foram essenciais para se conhecer a realidade da região estudada, dentre eles, as variáveis sócioeconômicas, o potencial da região, os fatores de risco para brucelose e o grau de conhecimento da população local, observando assim o risco de transmissão da doença entre bovinos ou mesmo ao homem.

Em relação aos aspectos socioeconômicos, chama muito a atenção, a elevada frequência $(35,1 \%)$ de renda familiar dos produtores com menos que um salário mínimo, além da maior frequência $(62,2 \%)$ de renda familiar de um a dois salários mínimos, o que nos mostra a baixa remuneração dos produtores, colocando-os em condição de vulnerabilidade, em que as principais fontes de renda são a produção leiteira e a venda de crias para outras propriedades. Fatores esses, quando não controlados podem representar risco para a disseminação e manutenção de doenças infecciosas como a brucelose (BRASIL, 2006; RADOSTITS et al. 2000).

$\mathrm{O}$ índice de analfabetismo é relativamente alto $(10,8 \%)$, tal como a quantidade de produtores com o ensino fundamental incompleto (73,0\%), essa baixa escolaridade é relatada 
como fator de risco para a transmissão de doenças infecciosas, como apresentado por Godoy \& Meira (2007), podendo assim, influenciar na compreensão das ações de controle, prevenção da doença em animais e nos comportamentos de proteção frente à disseminação de enfermidades para seres humanos.

O tipo de exploração pecuária mais frequentemente encontrado na região foi a mista, que se caracteriza pela criação de animais de corte e leite, havendo também, um alto fluxo de compra e venda de animais, possibilitando assim a transmissão entre rebanhos (RADOSTITS et al., 2000; POESTER et al., 2002; MONTEIRO et al.,2006).

O sistema de criação presente em todas as propriedades trabalhadas foi o extensivo, que por um lado dificulta a transmissão, devido à baixa densidade de animais por área; por outro, motivado pela não observação sistemática do rebanho e ambiente, a brucelose pode não ser detectada, pela dificuldade de observação imediata de sinais clínicos da doença como, por exemplo, esterilidade temporária ou permanente, repetição de cio, perdas na produção de leite e aborto de vacas prenhes no terço final da gestação, podendo expor outros animais a fetos abortados, envoltórios fetais ou mesmo descargas vaginais ricas em bactérias do gênero brucella (RADOSTITS et al. 2000; LAUAR, 1983; BRASIL, 2006).

Das propriedades analisadas, foi observada grande frequência com produção leiteira ativa, todas com a obtenção do leite por meio de ordenha manual, mostrando a baixa tecnificação das propriedades. Quanto à destinação do leite produzido no assentamento, apenas 12,9\% o entrega ao laticínio, que por sua vez efetua o tratamento térmico necessário para inativação da Brucella sp. (OMS, 1986; BRASIL, 2003), outros $12,9 \%$ declararam que produzem queijo fresco, feito a partir do leite in natura, tendo assim, um grande potencial de disseminação da doença a humanos (FREITAS, 2002). 74,2\% dos produtores que produzem leite consomem essa produção na propriedade ou comercializam parte dessa produção em propriedades vizinhas.

O consumo desse leite, dentro do assentamento, é feito, na maioria das vezes, cozido $(74,2 \%)$, o que pode ser considerado um fator de grande importância, pois de acordo com Brasil (2006) ocorre inativação da bactéria pelo calor. No entanto, ainda se observa aspectos culturais influenciando numa possível transmissão da doença, pois 25,8\% alegaram consumir o leite in natura, pelos mais diversos motivos, podendo ser um importante fator de risco para a brucelose humana (BRASIL, 2006).

Já o consumo de queijo fresco se revelou muito habitual, $43,2 \%$ das propriedades declararam consumir o queijo produzido no assentamento, podendo assim haver a infecção por Brucella para esses indivíduos, determinando a transmissão a humanos, se durante o processo não forem observadas normas de produção, como o tratamento térmico do leite (FERREIRA, 2002; FREITAS, 2002).

Em relação ao destino de animais para abate, se observou uma menor frequência de destinação de animais para abate em estabelecimentos inspecionados, a maior frequência fica para o abate na própria propriedade, o que pode trazer risco de infecção para as pessoas que cuidam da manipulação desses animais (BOYD et al. 1930; MAGNUSSON, 1933).

Outro aspecto investigado foi a comercialização de fêmeas, em que se observa uma alta frequência de compra e venda no terço final de gestação; esses animais, se infectados, podem contribuir com a disseminação da doença (RADOSTITS et al. 2000; CAMPOS et al. 2003; BRASIL, 2006).

No assentamento há um alto fluxo de animais entre propriedades, por apresentar elevado percentual de proprietários que fazem uso de aluguel de pasto para apascentar seus animais em determinadas épocas do ano. Há também, com $40,6 \%$, o uso de pasto comum a outras propriedades, havendo, portanto, aumento de risco pela proximidade de rebanhos (RADOSTITS et al. 2000).

A ocorrência de aborto nos últimos 12 meses foi relativamente baixa, o aborto é muito presente quando ocorre a entrada da doença em um rebanho e, posteriormente, se apresenta com uma frequência baixa, sendo considerado um sintoma clássico da ocorrência da brucelose em rebanhos (CAMPOS et al., 2003).

Outro fator importante foi à destinação e manipulação de fetos abortados e restos de parição, mesmo os que não registraram aborto nos últimos 12 meses foram questionados, nos quais 10,8\% alegaram manipular fetos abortados com a finalidade de enterrar esses animais, 
o que seria de muita valia para a interrupção da transmissão entre bovinos, porém, se não forem tomadas medidas de proteção individual necessárias, pode ocasionar na infecção do manipulador (CAMPAÑA et al., 2003). Já 89,2\% alegam deixar no local, não fazendo nenhum tratamento do ambiente, podendo assim contribuir para a manutenção do ciclo da doença entre animais (CAMPOS et al., 2003). Não houve registro de produtores que queimam a carcaça de fetos abortados no local, sendo esse o processo mais indicado pela inativação das bactérias através alta temperatura (BRASIL, 2006).

Com relação às ações previstas no PNCEBT, a vacinação de bezerras na faixa de 3 a 8 meses de idade é uma medida compulsória (BRASIL, 2006) que vem sendo praticada em todas as propriedades, por vacinadores capacitados e cadastrados junto ao serviço de defesa sanitária estadual, sendo efetuada em $83,8 \%$ dessas propriedades, duas vezes ao ano, e em $16,2 \%$, apenas uma vez ao ano. Nos casos em que a vacinação é realizada uma vez ao ano, podem ser justificados pela baixa quantidade de animais de algumas propriedades, bem como da sazonalidade de partos em determinados períodos do ano. A cobertura vacinal é uma das importantes ferramentas para o controle dessa enfermidade, pois, quando se encontra baixa, torna-se um fator preponderante para o aparecimento de casos humanos (CENTRO PANAMERICANO DE FEBRE AFTOSA, 2000).

O grau de conhecimento da população no que diz respeito à realização da vacinação contra brucelose, de certa forma, é satisfatório, tendo em vista que $70,3 \%$ conhecem a faixa etária correta para a aplicação da vacina nas bezerras, e o restante conhece o limite superior de idade de vacinação ( 8 meses), porém, afirmaram que o limite inferior seria o de quatro meses. Com relação à marcação das bezerras com ferro candente, $94,6 \%$ a realiza, o que nos mostra o cumprimento pela grande maioria das normas do PNCEBT.

A vacinação é efetuada através de vacinadores treinados e cadastrados pelo serviço de defesa, peças fundamentais para o bom andamento do programa de controle, por viabilizar, de forma mais simples, a aquisição da vacina, garantir o transporte, acondicionamento e sua correta aplicação. Das 37 propriedades, 97,3\% adquirem vacinas através do vacinador e 2,7\% adquirem diretamente da loja com receituário do Médico Veterinário.

A soroprevalência, obtida no assentamento para a brucelose, foi baixa, tanto para número de animais quanto para número de propriedades com a doença, o que mostra uma boa adesão dos produtores ao programa de controle, principalmente, com relação à vacinação de fêmeas, conforme já mencionado acima. Essa prevalência está abaixo das observadas na região centro-oeste, sendo de $6,8 \%$ dos animais testados positivos em 1975 (BRASIL, 2006); no Rio Grande do Sul, que após uma campanha de vacinação bem sucedida observou uma diminuição considerável na soropositividade de seu rebanho, passando de $2,0 \%$ em 1975 , para $0,3 \%$ em 1986 ; e no Paraná, de 9,6\%, em 1975 para 4,6\% em 1989 (BRASIL, 2006).

A variabilidade da prevalência de brucelose bovina é muito grande, dependendo não só de fatores de risco, mas também da adesão ao programa de controle da doença por parte dos produtores de cada região. Estudos mais recentes com bovinos de aptidões variadas mostram uma soroprevalência em rebanhos bovinos variando de $10,6 \%$ a $82,0 \%$ e em animais do mesmo rebanho, variando entre $1,9 \%$ a $10,2 \%$ (TOCANTINS, 2000; RIBEIRO et al., 2003; MATO GROSSO, 2004; MONTEIRO et al., 2006), em rebanhos leiteiros, as frequências podem variar de $1,22 \%$, conforme Poletto et al. (2004) realizando estudo em Passo Fundo Rio Grande do Sul, a 16,49\%, conforme trabalho de Palmquist (2001) no estado do Paraná.

Apenas uma propriedade apresentou um único bovino soropositivo ao teste de rotina (AAT), bem como ao teste confirmatório (2 ME). Essa propriedade possui tipo de exploração extensiva com aptidão para leite, com quatro animais de raça mestiça em lactação, produzindo em media 15 litros/dia, retirados em uma única ordenha diária; fatos esses que, além de propiciarem a transmissão da doença de animal para animal, podem infectar seres humanos por meio da ingestão de leite ou derivados sem tratamento térmico (OMS, 1986; BRASIL, 2003). Tal produção tem como destino um laticínio que recolhe leite da região, no qual é efetuada a pasteurização destruindo a brucella sp. O leite consumido na propriedade é feito apenas cozido, o que contribui 
para evitar a contaminação, pela ingestão, por parte dos moradores (BRASIL, 2006). Porém, o produtor, eventualmente, produz e consome queijo fresco na propriedade, o que eleva o risco de contaminação de humanos, considerando que o queijo fresco é produzido a partir do leite in natura, podendo apresentar bactérias do gênero brucella (FREITAS, 2002).

Para animais de abate, o destino mais comum é o de estabelecimento com inspeção Veterinária, porém, é declarada a compra e venda de fêmeas para reprodução, aluguel de pasto em alguma época do ano, além da presença de área de pasto comum a outras propriedades, sendo que esses fatores que podem contribuir para a transmissão da doença na região (RADOSTITS et al., 2000; CAMPOS et al., 2003). De acordo com o proprietário, não existe ocorrência de aborto nos últimos doze meses e que, quando houve tal problema, o produtor evitou a manipulação do mesmo, deixando tal animal no local em que se encontrava, o que também pode contribuir para a transmissão da doença entre animais (CAMPOS et al., 2003). Apesar de enviar os animais de abate para o destino correto, todos os outros fatores contribuem à disseminação da doença, podendo alguns deles até ser o responsável pelo caso positivo identificado no presente trabalho.

\section{Conclusão}

A maior parte dos produtores rurais do projeto de assentamento no município de Aragominas possui baixa escolaridade, baixa renda familiar o que pode colocar essas famílias em condições de vulnerabilidade.

Há presença de fatores de risco para a transmissão da doença entre animais no assentamento, cabendo destacar o alto fluxo de animais entre propriedades, seja por compra e venda, seja por aluguel de pasto ou pelo uso de pastagens comuns. Para seres humanos, também há a presença de fatores de risco sendo mais comum o consumo de leites e derivados in natura.

A frequência de animais soropositivos para a brucelose no projeto de assentamento do município de Aragominas foi baixa, o que se deve em grande parte a alta cobertura vacinal de bovinos, demonstrando uma grande adesão e efetividade do Programa de Controle e Erradicação de Brucelose e Tuberculose.

A não utilização de testes diagnósticos na aquisição, introdução de animais ou como rotina das propriedades é uma limitação para o monitoramento, controle e erradicação da Brucelose. 


\section{Referências}

1. ALTON, G.G.; MAW, J.; ROGERSON, B.A. Serological diagnosis of bovine brucellosis: an avaluation of the complement fixation, serum agglutination end rose bengal tests. Australian Veterinary Journal, v.51, n.2, p.57-63, 1975.

2. ALVAREZ, J. S.; GARCÍA, P. G. Incidência, etiologia y epidemiogía de la brecelosis en una área rural de la província de Lleida. Revista Española Salud Pública, v.74, n.1, p.45-53, 2000.

3. BENSEÑOR, I. M.; LUTUFO, P. A. Epidemiologia abordagem prática. São Paulo: Sarvier, 2005. 303 p.

4. BOYD, W.L., DELEZ, A.L., FITLH, C.P. The association of Bacterium abortus Bang with hygroma of the knee of castle. Cornell Veterinarian, v. 20, p. 263-268, 1930.

5. BRASIL. Ministério da Agricultura, Pecuária e Abastecimento. Boletim de Defesa Sanitária Animal: as doenças dos animais no Brasil. Histórico das primeiras observações. Brasília: Ministério da Agricultura, 1988. 101p.

6. BRASIL. Instrução Normativa /SDA no. 2 de 10 de Janeiro de 2001. Diário Oficial da União, 4 jun. 2001. Seção 1, p.26-31. Secretaria de Defesa Animal, Ministério da Agricultura, Pecuária e Abastecimento, Brasília. Disponível em: <http:/www. agricultura.gov.br /das/dda/programa html>. Acesso em: 11 fev 2002.

7. BRASIL. Ministério da Agricultura, Pecuária e Abastecimento. Manual Técnico do Programa Nacional de Controle e Erradicação da Brucelose e da Tuberculose PNCEBT. Brasília, 130p, 2003.

8. BRASIL. Ministério da Agricultura, Pecuária e Abastecimento. Manual Técnico do Programa Nacional de Controle e Erradicação da Brucelose e da Tuberculose PNCEBT. Brasília, 188p, 2006.
9. BRASIL. Portaria $\mathrm{N}^{\circ} 23$, de 20 de janeiro de 1976. Aprova as normas para profilaxia de brucelose animal. Diário Oficial da União, Ministério da Agricultura e do Abastecimento, Brasília, D.F., 16 de jan. 1976. Seção 1, p. 2266.

10. CAMPAÑA, R.C.; GOTARDO, D.J. \& ISHIZUCA, M.M. Coordenadoria de Defesa Agropecuária de São Paulo: Epidemiologia e profilaxia da brucelose bovina e bubalina. São Paulo, 2003. Disponível em: <http://www.cda.sp.gov. br/DocEst/Docs/bru/inf_doc_bru1.htm.> Acesso em nov. 2004.

11. CAMPERO, C. M. Brucelosis en toros: una revisión. Revista de Medicina Veterinária, v. 74, n. 1, 1993.

12. CAMPOS, A.C.P.; FRENEAU, G.E.; ACYPRESTE, C.S.; DIAS-FILHO, F.C.; BUENO, V.F.F.; SOUZA, J.P. \& REZENDE, L.C. Brucelose Bovina: Prevalência de anticorpos anti-Brucella bortus em reprodutores bovinos na microrregião de Goiânia. Ciência Animal Brasileira, v. 4, n. 2, p. 125-129, 2003.

13. CASAS OLASCOAGA, R. Diagnostico Serológico de la brucelosis. Centro Panamericano de Zoonosis, v. 18, $\mathrm{n}$. 3/4, p. 107-141, 1976.

14. CENTRO PANAMERICANO DE FIEBRE AFTOSA. Situacion de los programas de control de la fiebre aftosa, América del Sur. Rio de Janeiro, Brasil: PANAFTOSA/OPS/OMS; 74p, 2000.

15. FERREIRA, C.R. Espondilodisciste brucelósica: relato de caso. Revista da Sociedade Brasileira de Medicina Tropical, v. 35, p. 255-258, 2002.

16. FREITAS, J.A. Isolamento de Brucella sp em produtos de origem animal e significado em saúde pública. Revista de Ciências Agrárias, v. 37, p. 147-154, 2002. 
17. GODOY, I.; MEIRA, D.A. Soroprevalência da infecção chagásica em moradores de municípios da região de Botucatu, Estado de São Paulo. Revista da Sociedade Brasileira de Medicina Tropical, v. 40, p. 516-520, 2007.

18. LANGENEGGER, J. Brucelose. In: CHARLES,T. P.; FURLONG, J. Doenças dos bovinos de leite adultos. Coronel Pacheco: EMBRAPA - CNPGL, p. 8396, 1992.

19. LAUAR, N. M. Brucelose. Cati, São Paulo, n.169, 1983.

20. LORD, V.R.; SCHURIG, G.G.; CHERWONOGRODZKY, J.W.; MARCANO, M.J.; MELENDEZ, G.E. Field study vaccination of castle with brucella abortus strains RB 51 and 19 under high and low disease prevalence. American Journal of Veterinary Research, v. 59, n. 8, p. 1016-1020, 1998.

21. LUCAS. A. Simulação de impacto econômico da brucelose bovina em rebanhos produtores de leite das regiões Centro-Oeste, Sudeste e Sul do Brasil. 2006. 123 f. Tese (Doutorado em Medicina Veterinária) - Faculdade de Medicina Veterinária e Zootecnia. Universidade de São Paulo.

22. LUCERO, N. E.; ESCOBAR, G. I.; AYALA, S. M.; SILVA P.; NIELSEN, K. Fluorescence polarization assay for diagnosis of human brucellosis. Journal of Medical Microbiology, v. 52, n. 10, p. 883-887, 2003.

23. MAGNUSSON, H. Le bacile de L'avortement de Bang et les higromas des bovidés. Rev. Gén. Med. Vét., v. 42, p. 465-485, 1933.

24. MATO GROSSO (Estado). Instituto de Defesa Agropecuária do Estado de Mato Grosso: Brucelose no Mato Grosso. Cuiabá, 2004. Disponível em: <http:// www.indea.mt.gov.br/htlm/index.php $>$. Acesso em: 22 jan. 2007.
25. MEDRONHO, R. A.; CARVALHO, D. M.; BLOCH, K. V.; LUIZ, R. R.; WERNECK, G. L. Epidemiologia. São Paulo: Atheneu, 2006.

26. MONTEIRO, L. A. R. C.; PELLEGRINA, O.; ISHIKAWA, M. M.; OSÓRIO, A. L. A. R. Investigação epidemiológica de brucelose bovina em um estrato do Estado de Mato Grosso do Sul. Pesquisa Veterinária Brasileira, v. 26, n. 4, p. 217-222, 2006.

27. MURAKAMI, T. O. Epidemiologia da brucelose bovina nos municípios de Altinópolis e Santo Antônio da Alegria, Estado de São Paulo. Prevalência, fatores de risco e métodos diagnósticos. 2003. 103 f. Tese (Doutorado em Medicina Veterinária Preventiva) - Faculdade de Ciências Agrárias e Veterinária, Campus de Jaboticabal. Universidade Estadual Paulista.

28. NICOLETTI, P. The epidemiologyof bovine brucellosis. Advances in veterinary Science and Comparative Medicine, v. 24, n. 24, p. 69-98, 1980.

29. OMS. Organización Mundial de la Salud. Comitê Mixto FAO / OMS de expertos en brucelosis. Ginebra, Inf. Téc. 740, p.149, 1986.

30. PALMQUIST, O. K. Contribuições ao conhecimento da incidência da brucelose no Estado do Paraná (Brasil). Archives of Biology and Technology, v. 7, p. 307309, 2001.

31. POESTER, F. P. O risco da brucelose. Gado Holandez, Belo Horizonte, v. 63, n. $467,1997$.

32. POESTER, F. P.; GONÇALVES, V. S. P.; LAGE, A. P. Brucellosis in Brazil. Veterinary Microbiology, v. 90, p. 55-62, 2002. 
33. POLETTO, R.; KREUTZ, L. C.; GONZÁleS, J. C.; BERCELLOS, L. J. G. Prevalência de tuberculose, brucelose e infecções víricas em bovinos leiteiros do município de Passo Fundo, RS. Ciência Rural, v. 34, n. 2, p. 595-598, 2004.

34. RAdOSTITS, O. M.; GAY, C. C.; BLOOD, D. C.; HINCHCLIFF. K. W. Clínica veterinária. 9. ed. W.B. Saunders, 1877p., 2000.

35. RIBEIRO, A. R. P.; L O B A T O F.C.V.; ABREU, V.L.V.; FARIA E.S.; SILVA, J.A. Prevalência de tuberculose e brucelose no município de Ilhéus. Arquivo Brasileiro de Medicina Veterinária e Zootecnia, v. 55, n. 1, 2003. Disponível em: <http://www.scielo.br/ scielo.php?script $=$ sci_arttext\&pid $=\mathrm{S} 0102-$ 09352003000100021\&lng=pt\&nrm=iso $>$. Acesso em: 01 jan 2007.

36. SAMPAIO, I. B. M. Estatística aplicada à experimentação animal. $3^{\circ}$ ed. Belo Horizonte: Fundação de Estudos e Pesquisa em Medicina Veterinária e Zootecnia, 264 p., 2007.

37. TEIXEIRA, A. C. P.; SOUZA, C. F. A.; SÁ, M. J. S.; RIBEIRO, R. M. P.; OLIVEIRA, A. L.; SOUZA, R. M. Brucelose: zoonose controlada? Higiene Alimentar, v. 12, n. 54, p. 23-25. 1998.
38. THRUSFIELD, M. Epidemiologia Veterinaria. São Paulo: Roca, 2004. 556 p.

39. TOCANTINS S. Distribuição espacial da brucelose no gado bovino no Pantanal de Mato Grosso e relação com fatores ambientais. 2000. Tese de Mestrado, Curso de Biologia (Ecologia). Disponível em: <http//:www.cpap.embrapa.br/ agencia/congresso/8-25.cintra.htm $>$. Acesso em: 20 abril 2007.

40. USABIAGA, J. Zoonosis de importancia para la economía y para la salud pública: brucelosis $y$ tuberculosis bovina: control o eliminacion? Washington, D.C; Organización Panamericana de la Salud, 18 p, 2001.

41. WORLD HEALTH ORGANIZATION. Joint FAO/WHO Expert Committee on Brucelosis. Genebra: World Health Organization, p.58-66, (Technical Report Service, 740) 1986. 